\title{
The unconventional ones
}

\section{ce}

This was the

first hint that

there may be

more myosins

than those

found in

muscle.

KathleenTrybus

by
Hundred years after the discovery of muscle myosin (see Milestone 1), Pollard and Korn uncovered a second type of myosin, which exhibits notable differences from the classic form in its molecular organization and its effects on actin filaments.

Pollard and Korn were convinced that amoeboid movement was driven by a motility system based on actin filaments associated with the plasma membrane. Using the knowledge of the enzymatic properties of the muscle myosin, they set

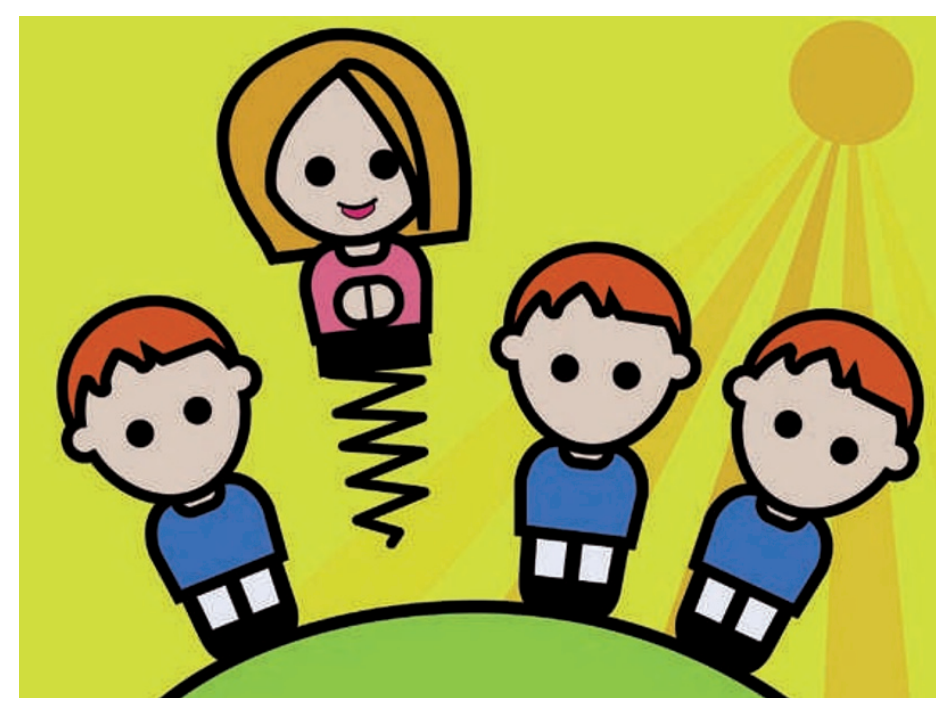

out to isolate an actin-dependent motor from Acanthamoeba castellanii biochemically. They purified an ATPase with properties that had previously been associated with muscle myosin: its activity in non-physiological high-salt concentrations was increased by potassium and inhibited by magnesium $(\mathrm{Mg})$, whereas the physiological Mg-ATPase was activated by actin. They purified two light chains associated with the novel enzyme, as well as the first cofactor that enhances the ATPase activity of a myosin, which was later identified as the p21-activated (PAK) kinase. This new ATPase, named myosin-I, could bind to and bundle filamentous actin.

The novel myosin was small compared with the conventional muscle myosin; in addition, whereas muscle myosin was a dimer that contained two ATPase domains, myosin-I was active as a monomer with a single ATPase region. These features generated much scepticism within the community: was myosin-I simply a catalytic degradation product of a traditional myosin more like the muscle form? Thirteen years later, Hammer and colleagues cloned the gene that encodes myosin-I, providing definitive evidence for the existence of this unusual myosin.

Following the bloom of sequencing analysis, research in the field flourished and many unconventional myosins were identified, each with distinctive molecular properties. Dimeric myosins do not necessarily form filaments as muscle myosin does, and some others, like myosin-VI, move in the opposite direction along the actin filaments. Unconventional myosins turned out to be involved in a wide range of functions that extend well beyond those envisaged when Pollard and Korn embarked on their search for the motor responsible for cell motility.

Nathalie Le Bot, Associate Editor, Nature Cell Biology

ORIGINAL RESEARCH PAPERS Pollard, T.D. \& Korn, E. D. Acanthamoeba myosin. I. Isolation from Acanthamoeba castellanii of an enzyme similar to muscle myosin. J. Biol. Chem. 248, 4682-4690 (1973) | Pollard, T. D. \& Korn, E. D. Acanthamoeba myosin. II. Interaction with actin and with a new cofactor protein required for actin activation of $\mathrm{Mg}^{2+}$ adenosine triphosphatase activity.J. Biol. Chem 248, 4691-4697 (1973)

FURTHER READING Hammer, J. A., Jung, G. \& Korn, E. D. Genetic evidence that Acanthamoeba myosin I is a true myosin. Proc. Natl Acad. Sci. USA 83, 4655-4659 (1986) | Fukui, Y., Lynch, T. J.,

Brzeska, H. \& Korn, E. D. Myosin I is located at the leading edges of locomoting Dictyostelium amoebae. Nature 341, 328-331 (1989) | Johnston, G. C., Prendergast, J. A. \& Singer, R. A. The Saccharomyces cerevisiae MYO2 gene encodes an essential myosin for vectorial transport of vesicles.J. Cell Biol. 113, 539-551 (1991)|

Espindola, F. S. et al. Biochemical and immunological characterization of $\mathrm{p} 190$ calmodulin complex from vertebrate brain: a novel calmodulin-binding myosin. J. Cell Biol. 118, 359-368 (1992) | Wells, A. L. et al. Myosin VI is an actin-based motor that moves backwards. Nature 401, 505-508 (1999) 